\title{
GESTÃO DE PESSOAS COMO DIFERENCIAL COMPETITIVO NAS INSTITUIÇÕES DE ENSINO TÉCNICO PROFISSIONALIZANTES DO MUNICÍPIO DE SANTA MARIA, RS
}

\author{
Mauro Rodrigo de Almeida Freitas ${ }^{1}$ \\ Francisco Nilton Gomes de Oliveira ${ }^{2}$
}

RESUMO: Este artigo é decorrente da necessidade de se abordar a temática "A Gestão de Pessoas como diferencial em escolas técnico profissionalizantes do município de Santa Maria, RS”. Dessa forma, esse artigo se caracteriza por ser uma abordagem teórica referente a gestão de pessoas, Educação Profissional e Tecnológica (EPT), e a importância da capacitação das pessoas envolvidas nesta área de atuação nas Instituições de Ensino Técnico Profissionalizantes. Utilizando como aspectos metodológicos, uma revisão bibliográfica sobre Gestão de pessoas, e Educação profissional e tecnológica. Os resultados, das leituras e referencias, traduz a gestão de pessoas como uma forma e ferramenta de gestão, fundamental e estratégica, nas ações implementadas pelas organizações como diferencial competitivo de mercado perante seus concorrentes.

Palavras-Chave: Gestão de pessoas. Instituições de ensino técnico profissionalizante. Diferencial competitivo

\footnotetext{
${ }^{1}$ Mestre em Educação Profissional e Tecnológica - UFSM. Especialista em Gestão de Pessoas (Feevale- NH). Graduado no Programa Especial de Graduação - Formação de Professores (PEGUFSM).E-mail: maurofreitas2004@yahoo.com.br

${ }^{2}$ Pós- Doutorado em Educação na Universidade Federal do Rio Grande do Sul- UFGRS. Atualmente é Professor Associado da Universidade Federal do Rio de Janeiro- UFRJ -Faculdade de Medicina Departamento de Terapia Ocupacional, docente do Mestrado Educação Profissional e Tecnológica no Colégio Técnico Industrial na Universidade Federal de Santa Maria, na linha de pesquisa: Políticas e Gestão em Educação Profissional e Tecnológica. Acumula experiência na área de Gestão em Educação superior, Direção de Ensino, Coordenação de cursos, Coordenação do Programa em Saúde Mental, Tutor e Preceptor da Residência Multiprofissional da UFSM. Avaliador de cursos do BASISINEP/MEC. Linhas de Pesquisas: Gestão em Educação Superior: Políticas públicas, Gestão e Avaliação, Interdisciplinaridade, bem como na Terapia Ocupacional em Saúde Mental, Saúde Coletiva e Campo Social. Autor dos Livros: O universo linguístico: uma releitura filosófica na linguagem humana; Cenários e determinantes na educação superior no Brasil: caminhos reflexões sobre as práticas institucionais de ensino e Educação Superior: refletindo caminhos e compartilhando relatos de experiências, modelos e experiências de uma rede de atenção em saúde mental e Acessibilidade Cultural no Brasil: narrativas e vivências em ambientes sociais. Atualmente é Pesquisador na Rede de Estudos em Universidade (Rede GEU) da Universidade Federal de Santa Maria- UFSM, numa interlocução interinstitucional das Universidades Federais de Santa Maria (UFSM) e Porto Alegre (UFRGS) e Docente do Programa de Pós Graduação de Educação Profissional e Tecnológica do Colégio Técnico Industrial de Santa Maria- UFSM. E-mail: niltonufrj@gmail.com, nilton@medicina.ufrj.br.
} 
ABSTRACT: His article arises from the need to address the theme "People Management as a differential in vocational technical schools in the city of Santa Maria, RS". Thus, this article is characterized by being a theoretical approach referring to people management, Professional and Technological Education (EPT), and the importance of training people involved in this area of activity in Vocational Technical Education Institutions. Using as methodological aspects, a bibliographical review on People Management, and Professional and Technological Education. The results, from readings and references, translate people management as a fundamental and strategic management tool and form, in the actions implemented by organizations as a competitive differential in the market vis-à-vis their competitors.

Keywords: People management. Vocational technical education institutions. competitive edge.

\section{INTRODUÇÃO}

O alto índice de crescimento de cursos técnicos profissionalizantes nos últimos anos, e o investimento, tanto do setor público quanto do privado em cursos deste formato, faz com que o grande diferencial competitivo seja ou não, o formato de gestão e capacitação das pessoas envolvidas nesta área de atuação em relação às instituições concorrentes A gestão inovadora, as novas tecnologias, a capacitação, treinamento e desenvolvimento tornam-se imprescindíveis neste processo de inovação de ensino e aprendizagem.

No decorrer das minhas atividades pessoais e profissionais, seja atuando com treinamentos em empresas, seja fazendo palestras motivacionais em instituições de ensino pública e/ou particular, com intuito de proporcionar aos estudantes a acreditarem mais no seu potencial na vida pessoal e profissional, me deparei com alunos focados em seus objetivos, em outros momentos nem tanto, devido a vários aspectos.

Aspectos estes, em algumas instituições de ensino técnico profissionalizantes, em especial as instituições privadas, a finalidade na maioria das vezes é mercadológica, na busca de resultados, lucros, em não somente na aprendizagem e nos objetivos de cada aluno.

Percebi, inicialmente, também que nada seria realizado senão fossem as pessoas envolvidas e, principalmente a forma de gestão destas pessoas nestas instituições. 
Para sociedade uma resposta positiva de "pós-venda", de uma entrega correta do serviço ofertado aos alunos e seus familiares, atendendo o que se realmente se está buscando como auxilio e complemento na formação acadêmica é de extrema relevância.

Profissionalmente destaca-se também o fator qualidade nestes serviços, a qualificação, a formação dos sujeitos envolvidos (professores, gestores). O profissionalismo prestado no que é proposto como ensino.

Esta busca pela qualificação, formação, capacitação dos professores e gestores, concomitante com uma gestão adequada de pessoas, na minha percepção é fundamental para o êxito no processo de entrega de um ensino de qualidade por parte das instituições de ensino técnico profissionalizantes, em destaque nas privadas, na qual a busca pelo resultado é constante.

A ideia de Gestão de Pessoas tem avançado ao longo do tempo acompanhando as próprias mudanças do mercado e dos processos de gestão e inovação, servindo como ferramentas e instrumento capaz de desenvolver e potencializar, o que se tem de melhor em cada sujeito envolvido nestas instituições de ensino como diferencial no modelo de ensino e aprendizagem.

Este texto tem-se como objetivo geral descrever a Gestão de Pessoas como diferencial de competitividade no Ensino Técnico e Profissionalizante no município de Santa Maria, RS.

Apresenta-se uma conceituação geral de gestão de pessoas com vistas a elaborar um melhor conhecimento acerca da temática proposta.

A problematização do tema em questão se dá mediante formas e métodos de gestão de pessoas exercidas em algumas instituições de Ensino Técnico Profissionalizantes no município de Santa Maria, RS.

Trata-se de uma revisão bibliográfica de caráter exploratório e descritivo.

\section{A GESTÃO DE PESSOAS COMO DIFERENCIAL COMPETITIVO}

A moderna dinâmica das relações de trabalho e as exigências do próprio mercado têm impulsionado os gestores a pensarem seriamente sobre o aspecto da 
gestão de pessoas e o suporte necessário aos recursos humanos na melhoria contínua de seu desempenho. Atualmente, a grande concorrência entre as organizações, faz com que as mesmas busquem profissionais qualificados e dinâmicos.

Portanto, é de suma importância que as mesmas possuam uma política de gestão de pessoas centrada em ajustar o potencial humano e retê-lo, com ferramentas e alternativas de planejamento e desenvolvimento de seus envolvidos.

Uma nova era vem se estabelecendo rapidamente para aqueles que praticam a Gestão de Pessoas nas organizações e, atualmente, para uma empresa manter-se competitiva precisa, mais do que nunca, compreender o elemento humano e desenvolver a educação corporativa que trará resultados mais completos para a organização. Vários fatores contribuem para isso: as mudanças econômicas, tecnológicas, sociais, culturais, legais, políticas, demográficas e ecológicas que atuam de maneira conjugada e sistêmica, em um campo dinâmico de forças que produz resultados inimagináveis, trazendo imprevisibilidade e incerteza para as organizações. As pessoas significam o principal diferencial competitivo que mantém e promovem o sucesso organizacional. Constituem-se a competência básica da organização.

As organizações investem nas pessoas para utilizá-las plenamente em suas atividades de produção e seus serviços dependem das pessoas para alcançar sucesso (produtividade, lucratividade, competitividade, qualidade, novos clientes, imagem). Em contrapartida as pessoas também dependem das organizações para atingir os objetivos pessoais (melhores salários, satisfação, qualidade de vida, crescimento), beneficiando a todos neste processo.

Frente a essas transformações sociais, as empresas começaram a ter diferentes visões do mundo, do trabalho, do relacionamento interpessoal e da tecnologia.

A ideia de Gestão de Pessoas tem avançado ao longo do tempo acompanhando as próprias mudanças do mercado e dos processos de gestão: "O desafio lançado para gestão de pessoas é como encarar cada pessoa considerando sua individualidade e como gerencia-la dentro de ambientes de diversidades” (DUTRA, 2009, p. 2I).

A provável tendência das organizações é a de manter um pequeno órgão central de recursos humanos, de alto nível, com grande domínio dos assuntos dessa 
área e bons conhecimentos dos negócios da empresa, para consultoria interna e apoio aos gerentes de linha. Lacombe (2005) afirma que os novos métodos de administração se preocupam essencialmente com a administração das pessoas, bem como este planejamento dos recursos humanos tem de ser organizado como parte do planejamento estratégico da empresa.

O cenário da Gestão de Pessoas nas organizações ascendeu de atividades operacionais e legislativas para ações corporativas estratégicas. As mudanças derivam da nova economia: da era digital, dos novos paradigmas na gestão organizacional.

Empresas são feitas de pessoas para pessoas. A pedra fundamental da gestão de pessoas está na contribuição conceitual e prática para uma vida humana mais saudável e com resultados legítimos de produtividade, qualidade e desenvolvimento e competitividade sustentável (FRANÇA, 2010).

Do contrário, muitos recursos serão desperdiçados: serão contratadas pessoas que não se encaixam nos programas previstos, as equipes poderão estar superdimensionadas ou aquém do necessário em quantidade e qualidade, a condução inadequada da equipe pode levar à falta de motivação e até a fuga de talentos. Entretanto, as práticas de gestão de pessoas devem estar integradas entre si, onde os valores dos gestores precisam estar alinhados à política organizacional a fim de assegurar que os métodos sejam aplicados de forma coesa. Tendo em vista que, se trata de uma nova era além de dominar as técnicas de gestão de pessoas, o profissional necessita conhecer profundamente os negócios da empresa onde trabalha e entender de suas estratégias (ARAUJO, 2006).

Para Milkovich (2008), toda organização precisa ainda identificar, conquistar, desenvolver, remunerar e fazer prosperar seus recursos humanos.

Segundo Robbins (1999, p.o3),

Toda a organização é constituída por pessoas. Obter seus serviços, desenvolver suas habilidades, motivá-las para altos níveis de desempenho e assegurar que continuem a manter seu comprometimento com a organização são essenciais para se alcançarem os objetivos organizacionais. Recrutar e manter bons empregados é fundamental para o sucesso de uma organização. 
Assim, o contexto em que se situa a Gestão de Pessoas é representado pelas organizações e pelas pessoas. Sem organizações e sem pessoas não haveria a Gestão de Pessoas. As organizações são constituídas de pessoas e dependem delas para atingir seus objetivos e cumprir suas missões. E para as pessoas, as organizações constituem o meio através do qual elas podem alcançar vários objetivos pessoais, com um custo mínimo de tempo, esforço e de conflito. Muitos dos objetivos pessoais jamais poderiam ser alcançados apenas por meio do esforço pessoal isolado. As organizações surgem para aproveitar a sinergia dos esforços de várias pessoas que trabalham em conjunto (DESSLER, 2003).

A gestão de pessoas é uma área muito sensível à mentalidade que predomina nas organizações que ela é contingencial e situacional, pois depende de vários aspectos, como a cultura que existe em cada organização, da estrutura organizacional adotada, das características do contexto ambiental, do negócio da organização, da tecnologia utilizada, dos processos internos e de uma infinidade de outras variáveis importantes (FRANÇA, 2010).

Segundo Bitencourt (2010), o sistema de gestão de pessoas é um processo sistêmico, contingencial e situacional, sendo influenciado por forças externas (quantidade e qualidade do talento humano disponível no mercado, ações dos movimentos sociais e sindicais, ações do Estado, etc.) e internas (cultura e valores da organização, mudanças no processo produtivo, negócios da organização, etc.). Portanto, não há apenas uma melhor forma de gerir pessoas.

\section{I Conceitos de gestão de pessoas}

A Gestão de Pessoas analisada pelos enfoques comportamental e administrativo relaciona-se com os mais variados fatores organizacionais:

a) Novas tecnologias

b) Treinamento e Desenvolvimento

c) Remuneração e Benefícios

d) Banco de Talentos

e) Segurança, Saúde, Qualidade de Vida

f) Gestão e Qualidade 
A complexidade e a expansão destes fatores organizacionais refletem inclusive na terminologia: Recursos Humanos ou Gestão de Pessoas. A Gestão de Pessoas deve ocorrer a partir da visão integrada das pessoas e das questões fundamentais: as expectativas sobre relações de trabalho, o contrato psicológico que a pessoa quer da empresa e o que a empresa quer do seu pessoal.

Esses conceitos e processos comportamentais (dedicação, vínculos na empresa, significado do trabalho e competência) devem estar presentes nos modelos, processos e práticas nas empresas, daí a razão de conhecer os aspectos comportamentais integrados aos administrativos (FRANÇA, 2010).

Perfis e tipos de personalidade, grupos, equipes, lideranças, processos de cooperação, competição, apatia, cultura organizacional, valores, questões éticas, aspectos da vida social, são aspectos e fatores em destaque no processo de gestão de pessoas para uma organização.

A Gestão de Pessoas depende destes fatores existentes em cada organização, da sua estrutura organizacional adotada, das características do contexto ambiental, do negócio da empresa, da tecnologia utilizada, dos processos internos e de uma infinidade de outras variáveis.

\section{I.I Aspectos fundamentais da gestão de pessoas}

- As pessoas como seres humanos: personalidade, diferentes entre si, história pessoal, conhecimentos, habilidades e competências;

- As pessoas são vistas como parceiros da organização: capazes de conduzi-la ao sucesso, esforço, dedicação, responsabilidade, comprometimento. Investem esperando retorno.

Gestão de Pessoas é um conjunto das forças humanas voltadas para as atividades produtivas, gerencias e estratégicas dentro de um ambiente organizacional (FRANÇA, 2010). Forças: potenciais com criatividade, inovação, força de trabalho, interação e compromisso.

Para Chiavenato (2010), Gestão de Pessoas é uma área muito sensível à mentalidade que predomina nas organizações. É contingencial e situacional, pois depende de vários aspectos: cultura e estrutura organizacional, características do 
contexto ambiental, do negócio da organização, da tecnologia, dos processos internos e do estilo de gestão, etc.

O autor também destaca que Gestão de Pessoas como sendo uma área que constrói talentos por meio de um conjunto de processos que cuida do colaborador nas organizações.

Com isto, Gestão de Pessoas é percebida como conjunto integrado de atividades de especialista e de gestores - como agregar, aplicar, recompensar, desenvolver, manter e monitorar pessoas - no sentido de proporcionar competências e competitividade à organização.

Todos esses processos estão intimamente relacionados entre si, de tal maneira que se interpenetram e se influenciam reciprocamente. Cada processo tende a favorecer ou prejudicar os demais, quando bem ou mal utilizado. O equilíbrio na condução de todos esses processos é fundamental, são desenhados de acordo com as exigências e das influências ambientais externas e organizacionais internas para obter a melhor compatibilização entre si. Deve funcionar como um sistema aberto e interativo (CHIAVENATO, 20I0).

Figura I - Processos e Gestão de Pessoas

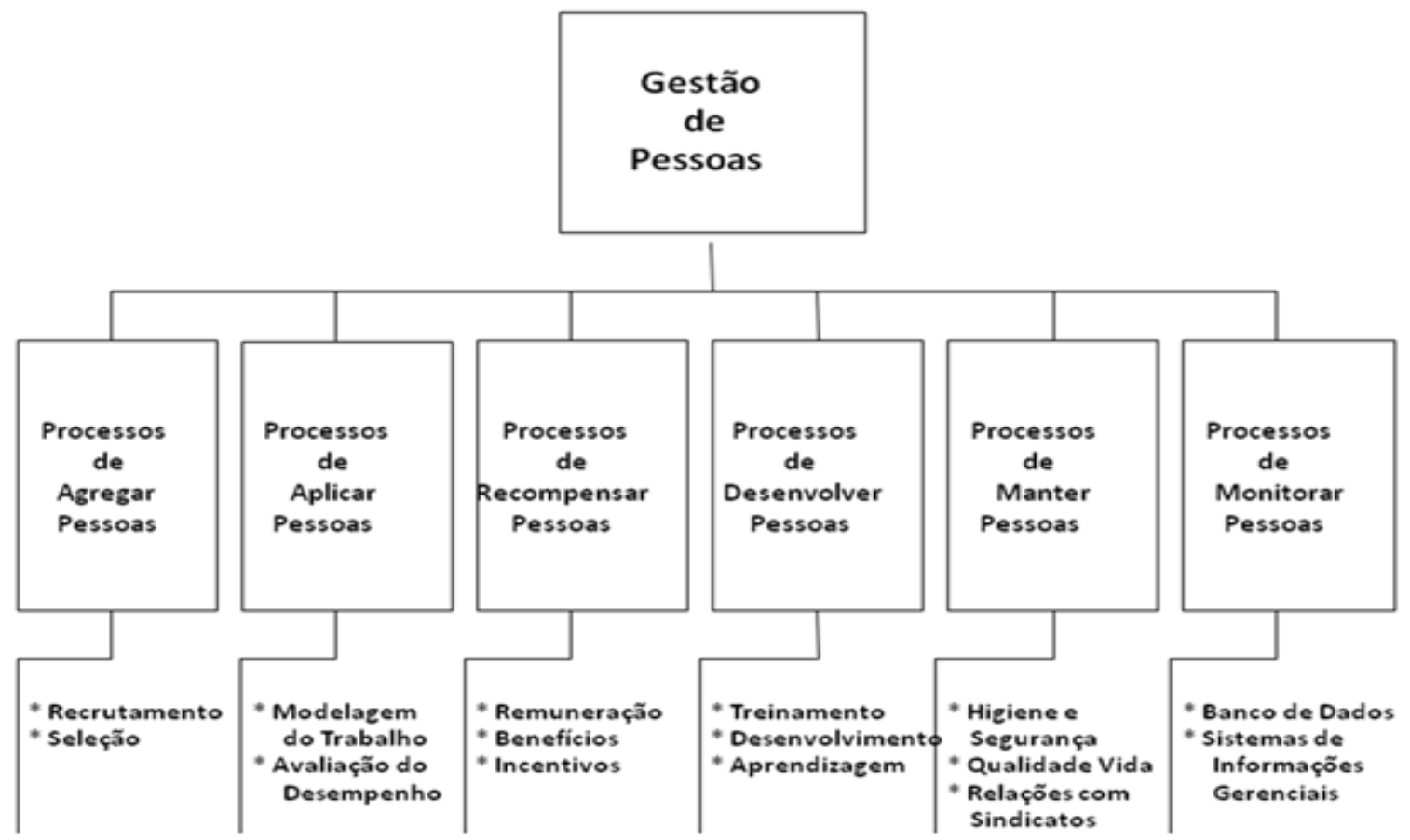

Fonte: Chiavenato (2010, p. 15). 


\section{A FORMACÃO E A CAPACITACÃO DAS PESSOAS COMO PROCESSO FUNDAMENTAL NO COMPORTAMENTO ORGANIZACIONAL}

Todo colaborador possui conhecimentos, habilidades e atitudes e, com o treinamento e desenvolvimento para uma gestão focada nas pessoas, esses três itens são aperfeiçoados, uma vez que eles já estão em cada pessoa de modo particular. Para Marras (2002, p.I45), o "treinamento é um processo de assimilação cultural em curto prazo, que objetiva repassar ou reciclar conhecimentos, habilidades ou atitudes". A gestão de pessoas cresce cada vez mais em relevância para as organizações, tornandose um diferencial no contexto atual. Disso, vê-se a necessidade de capacitá-los para suas funções. Gil (2007, p.I2I) declara que "o treinamento, de acordo com a concepção tradicional, é o meio para adequar cada pessoa a seu cargo, com vista no alcance dos objetivos da organização".

O mundo do trabalho modificou-se nas últimas décadas. Dessa forma, percebe-se que a administração de Gestão de Pessoas adquire função significante nas empresas, instituições de ensino, na qual podem nomear estratégias de treinamento e valorização, assim como estruturar e colocar em prática cursos de capacitação e qualificação dos sujeitos envolvidos.

As exigências atuais são por constante aperfeiçoamento técnico, teórico e prático, com intuito de potencializar as habilidades, atitudes e novos conhecimentos necessários para o crescimento pessoal e profissional.

Paralelamente, as ações educacionais corporativas têm feito uso das novas tecnologias, em particular, as inovações digitais, tais como aplicativos digitais, ferramentas de estudos.

O treinamento e a capacitação proporcionam um potencial de benefícios para as organizações, sendo que o conhecimento e prática durante o trabalho pode funcionar como uma alavanca estratégica para aprimorar os resultados. E dentro dessa nova realidade, surge uma oportunidade: a falta de tempo disponível facilita a entrada de tecnologias e metodologias de aprendizado como ferramentas 
catalisadoras, acelerando os processos do programa de treinamento e desenvolvimento em larga escala (BOOG; BOOG, 2013).

Toda organização precisa ter colaboradores ajustados, treinados e experientes para desempenhar as atividades necessárias. À medida que os cargos exercidos nas organizações de hoje tornaram-se mais complexos, aumenta a importância na capacitação dos envolvidos. Quando os cargos eram simples, fáceis de aprender e influenciados apenas num grau mínimo pelas mudanças tecnológicas, havia pouca necessidade de os empregados melhorarem ou alterarem suas habilidades. Mas essa situação raramente existe hoje. Em vez disso, estão ocorrendo rápidas mudanças nos cargos, exigindo novas habilidades, novos conhecimentos por parte dos empregados.

Chiavenato (2010, p. 367),

Treinamento é o processo sistemático de alterar o comportamento dos empregados na direção do alcance dos objetivos organizacionais. $O$ treinamento está relacionado com as atuais habilidades e capacidades exigidas pelo cargo. Sua orientação é ajudar os empregados a utilizar suas principais habilidades e capacidades para serem bem-sucedidas.

A empresa do século XXI vive em uma economia em que mais e mais valor agregado será criado pelo capital humano, a aprendizagem e o trabalho são essencialmente o mesmo fato, com ênfase no desenvolvimento da capacidade do indivíduo de aprender, valorizar o trabalho em equipe na avaria do individualismo, sai à procura de mercados globais em detrimento dos colaboradores e enfoca as necessidades do cliente em lugar do lucro no curto prazo (MEISTER, 1999).

O treinamento é uma experiência de aprendizagem que busca mudanças relativamente permanentes numa pessoa, a fim de melhorar sua capacidade de desempenho no cargo, promovendo mudanças de habilidades, conhecimentos, atitudes ou comportamentos.

Pode significar, em suma, mudar o que os empregados sabem, o modo como trabalham, suas atitudes em relação ao trabalho, ou sua interação com os colegas de trabalho ou com o supervisor (ROBBINS; DECENZO, 200I).

Para o mesmo autor, o treinamento é mais orientado para o presente; seu foco é nos cargos atuais das pessoas, acentuando suas habilidades e capacidades específicas para o desempenho imediato. O desenvolvimento do sujeito, por outro lado, focaliza em geral nos cargos futuros na organização. À medida que você progride em seu 
cargo e carreira, vai precisar de novas habilidades e capacidades. Seja como for, o foco no resultado é sempre exigido.

No passado, alguns especialistas em Recursos Humanos, consideravam treinamento um meio para adequar cada pessoa a seu cargo e desenvolver a força de trabalho da organização a partir do preenchimento de cargos. Mais recentemente, o conceito foi ampliado, considerando o treinamento como um meio para alavancar o desempenho no cargo. Quase sempre o treinamento tem sido entendido como o processo pelo qual a pessoa é preparada para desempenhar de maneira excelente as tarefas específicas do cargo que deve ocupar. Modernamente, o treinamento é considerado um meio de desenvolver competências das com finalidade de que se tornem mais produtivas, criativas e inovadoras, a fim de contribuir melhor para objetivos organizacionais e se tornarem cada vez mais valiosas (CHIAVENATO, 2010).

Treinamento é um processo de assimilação cultural em curto prazo, que objetiva repassar ou reciclar conhecimentos, habilidades e atitudes relacionados diretamente à execução de tarefas ou à sua otimização no trabalho. O treinamento produz um estado de mudança no conjunto de Conhecimento, Habilidades e Atitudes (CHA) de cada trabalhador, uma vez que implementa ou modifica a bagagem particular de cada um. Todos são possuidores de uma bagagem de conhecimentos, habilidades e atitudes referentes à trajetória particular de cada um. Essa bagagem constitui o CHA individual que deve estar em uníssono com a posição ocupada numa estrutura organizacional e com as responsabilidades devidas. Eventuais diferenças ou carências de CHA em relação às exigências do cargo ocupado podem ser corrigidas por meio de treinamento (MARRAS, 2002).

De acordo com Boog (1999), Treinamento e Desenvolvimento são uma das mais poderosas ferramentas de transformação no mundo organizacional. A área de $T \& D$ passa a ter uma estrutura reduzida, com um forte componente de consultoria interna, apoiando processos de mudança individual e grupal, isto é, o papel é o de coordenar e apoiar os processos de mudança; ou seja, deve contribuir para a conquista equilibrada e simultânea dos resultados da empresa e dos indivíduos que nela trabalham. 
A prática demonstra que atualmente as empresas têm apresentado uma grande preocupação com o investimento em treinamento e desenvolvimento em seus profissionais. Cada vez mais, observam-se evidências suficientes para afirmar que, quanto mais as organizações investem na capacitação de seus colaboradores, mais acertos apresentam, obtendo melhores desempenhos em suas estratégias e objetivos organizacionais.

Treinamento é um processo sistemático para promover a aquisição de habilidades, regras, conceitos ou atitudes que resultem em uma melhoria da adequação entre as características dos empregados e as exigências dos papéis funcionais. Desenvolvimento é o processo de longo prazo para aperfeiçoar as capacidades e motivações dos empregados a fim de torná-los futuros membros valiosos da organização. O desenvolvimento inclui não apenas o treinamento, mas também a carreira e outras experiências (MILKOVICH; BOUDREAU, 2008).

Segundo Chiavenato (2010), o processo praticado atualmente pelas organizações nos programas de treinamento é dividido em quatro etapas: diagnóstico (levantamento das necessidades ou carências de treinamento a serem atendidas ou satisfeitas), programação (elaboração do projeto ou programa de treinamento para atender às necessidades diagnosticadas), implementação (execução e condução do programa de treinamento) e avaliação (verificação dos resultados obtidos com o treinamento).

Conforme Lacombe (2005), a principal razão pela qual as empresas treinam é para proporcionar ao empregado novas habilitações ou melhorar as que o mesmo possui, portanto, deve produzir mais e melhor para a empresa, proporcionando um retorno ao investimento que a empresa fez em treinamento.

As organizações podem usar o treinamento como uma ferramenta estratégica para atingir os objetivos da empresa e de seus empregados. A ligação entre treinamento e objetivos acaba sendo esquecida no cotidiano pela implementação de programas e no enfrentamento de crises. O treinamento torna-se uma atividade, não uma estratégia (MILKOVICH; BOUDREAU, 2008).

O papel das organizações no aprendizado de seus funcionários está se ampliando cada vez mais. A educação corporativa põe o foco no desenvolvimento do 
quadro de pessoas com vistas a obter resultados nos negócios. É um modelo diferente de treinamento tradicional, feito para transmitir conhecimentos específicos do assunto em que a pessoa apresenta alguma deficiência, por trazer uma visão mais ampla e de longo prazo (CHIAVENATO, 20I0).

Para o mesmo autor, o gerenciamento do conhecimento procura alinhar a educação das pessoas aos objetivos estratégicos do negócio. As organizações que estão privilegiando a educação corporativa criaram suas universidades próprias: as universidades corporativas. Não há necessidade de construir prédios ou salas de aula. Em muitos casos, o conceito de universidade corporativa existe, mas a estrutura é virtual; utiliza-se do conceito de realidade virtual. $O$ resultado final desse redirecionamento do treinamento é a melhoria dos serviços oferecidos e, consequentemente, dos lucros. A educação corporativa está se tornando uma necessidade competitiva, pois representa algo muito além do treinamento.

Em relação a Educação Profissional e Tecnológica (EPT), sobressai-se a intenção educativa de formar, produzir a subjetividade de sujeitos capazes de raciocinar, pensar, realizar e ter um posicionamento crítico sobre suas ações, além de desenvolver habilidades e competências que potencializem a sua inserção qualificada no mundo do trabalho (SANTOS, 2017).

Para o mesmo autor, concomitante a ampliação do ensino profissional, com vistas a suprir a necessidade de qualificação de mão de obra para o mundo do trabalho, cresceu a demanda pela formação de professores capacitados a atuar no ensino profissionalizante.

Ocorrem também alguns pressupostos que alicerçam a Educação Profissional e Tecnológica (EPT): articulação do ensino profissionalizante com a Educação Básica, a integração do ensino profissionalizante ao mundo do trabalho e a valorização dos profissionais de ensino profissionalizante (BRASIL, 2004 apud SANTOS, 2017).

Com base nesta demanda de gestão e de formação adequada das pessoas envolvidas no processo de ensino técnico profissionalizante que temos como propósito fazer uma pesquisa futura na busca de possíveis respostas para melhor forma de gestão nestas organizações de ensino. 


\section{CONCLUSÃO}

Este artigo buscou apresentar os conceitos de Gestão de Pessoas, a importância da capacitação e formação destas pessoas envolvidas em um processo dentro de uma organização.

Destacou também que uma gestão de pessoas adequada incorporada como um elemento estratégico nas organizações, faz com que as ações implementadas tenham como objetivo principal resultados positivos de desenvolvimento pessoal e profissional dos envolvidos.

Descreveu a relevância da gestão de pessoas como fator importante nas organizações, vista como agente de mudança e de geração de esforços para transformação organizacional, resultando em maior competitividade.

Nesta concepção entender a evolução e os desafios de gestão de pessoas na organização é de suma importância para os envolvidos no processo de gestão. Pois é um processo que vem ocorrendo há séculos e abrange discussões em vários campos de conhecimento (AVILA; STECCA, 2015).

No campo escolar, deslumbra então a possibilidade uma pesquisa futura na dimensão de destaque na gestão de pessoas como diferencial competitivo entre as instituições de ensino técnico profissionalizante.

A percepção dos aspectos que envolvem o trabalho do gestor de pessoas, aliando-os aos pressupostos da Educação Profissional e tecnológica, não se constitui uma tarefa simples.

Diferentes sujeitos envolvidos, como alunos, coordenadores, professores, faz com que os gestores busquem cada vez mais ferramentas e propostas para atender as inúmeras expectativas geradas no processo de melhoria, formação e capacitação destes sujeitos.

Procurou-se, neste artigo, então pontuar os conceitos de gestão de pessoas, sua relevância na gestão das organizações e sua importância como diferencial competitivo como a qualificação e formação dos atores envolvidos em uma instituição de ensino técnico profissionalizante, sejam eles (professores, gestores, coordenadores e alunos). 
Por conseguinte, o caminho será a busca de dados junto as Instituições de Ensino Técnico Profissionalizante no município de Santa Maria, RS, com intuito de verificar como está sendo ou não praticada assertivamente a gestão de pessoas nestas organizações.

\section{REFERÊNCIAS}

ARAUJO, L. C. G. Gestão de pessoas: estratégias e integração organizacional. São Paulo: Atlas, 2006.

AVILA, L. V.; STECCA, JP. Gestão de pessoas. Santa Maria: Universidade Federal de Santa Maria, Colégio Politécnico; Rede e-Tec Brasil, 2015.

BITENCOURT, C. Gestão contemporânea de pessoas: novas práticas, conceitos tradicionais. 2. ed. Porto Alegre: Bookman, zoro.

BOOG, G. G. Manual de treinamento e desenvolvimento. ABTD. 3. ed. São Paulo: Makron Books, 1999.

BOOG, G. G.; BOOG, M. Manual de treinamento e desenvolvimento: processos e operações. 6. ed. São Paulo: Pearson Education do Brasil, 2013.

BOHLANDER, George; SNELL, Scott; SHERMAN, Arthur. Administração de recursos humanos. São Paulo: Pioneira Thomson Learning, 2005.

CARVALHO, Antonio Vieira de; NASCIMENTO, Luiz Paulo do. Administração de recursos humanos. 2. ed. São Paulo: Pioneira, 1997.

CHIAVENATO, Idalberto. Administração de recursos humanos. 2. ed. São Paulo: Atlas, 198I.

Introdução à teoria geral da administração. 5. ed. Rio de Janeiro: Campus, I999.

Gestão de pessoas: e o novo papel dos recursos humanos nas organizações. 2. ed. Rio de Janeiro: Elsevier, 2004.

Gestão de pessoas: e o novo papel dos recursos humanos nas organizações. 3. ed. Rio de Janeiro: Elsevier, 2oro.

DESSLER, G. Administração de recursos humanos. São Paulo: Prentice Hall, 2003.

DUTRA, J. S. Gestão de pessoas: modelo, processos, tendências e perspectivas. São Paulo: Atlas, 2009. 
FRANÇA, A. C. L. Práticas de recursos humanos PRH: conceitos, ferramentas e procedimentos. São Paulo: Atlas, 2010.

GIL, A. C. Gestão de pessoas. São Paulo: Atlas, 2007.

Métodos e técnicas de pesquisa social. 5. ed. São Paulo: Atlas, 2006.

LACOMBE, F. J. M. Recursos humanos: princípios e tendências. São Paulo: Saraiva, 2005 .

MARRAS, J. P. Administração de recursos humanos: Do operacional ao estratégico. 3. ed. São Paulo: Futura, 2000.

Administração de recursos humanos. 3. ed. São Paulo: Futura, 2002.

MASCARENHAS, A. O. Gestão estratégica de pessoas. São Paulo: Cengage Learning, 2008.

MATTAR, F. N. Pesquisa de marketing, metodologia, planejamento. 3. ed. São Paulo: Atlas, 1996.

MEISTER, J. C. Educação corporativa. São Paulo: Makron Books, 1999.

MILKOVICH, G. T.; BOUDREAU, J. W. Administração de recursos humanos. São Paulo: Atlas, 2008.

ROBBINS, S. P. Comportamento organizacional. Rio de Janeiro: LTC, 1999.

ROBBINS, S. P.; DECENZO, D. A. Administração de recursos humanos. 6. ed. Rio de Janeiro: LTC, 2001.

SANTOS, C. B. Do Bacharel à docência: a percepção dos egressos do PEG/UFSM quanto a atuação profissional docente. 2017. 88f. Dissertação (Mestrado em Educação Profissional e Tecnológica). Universidade Federal de Santa Maria, Santa Maria, 2017. 